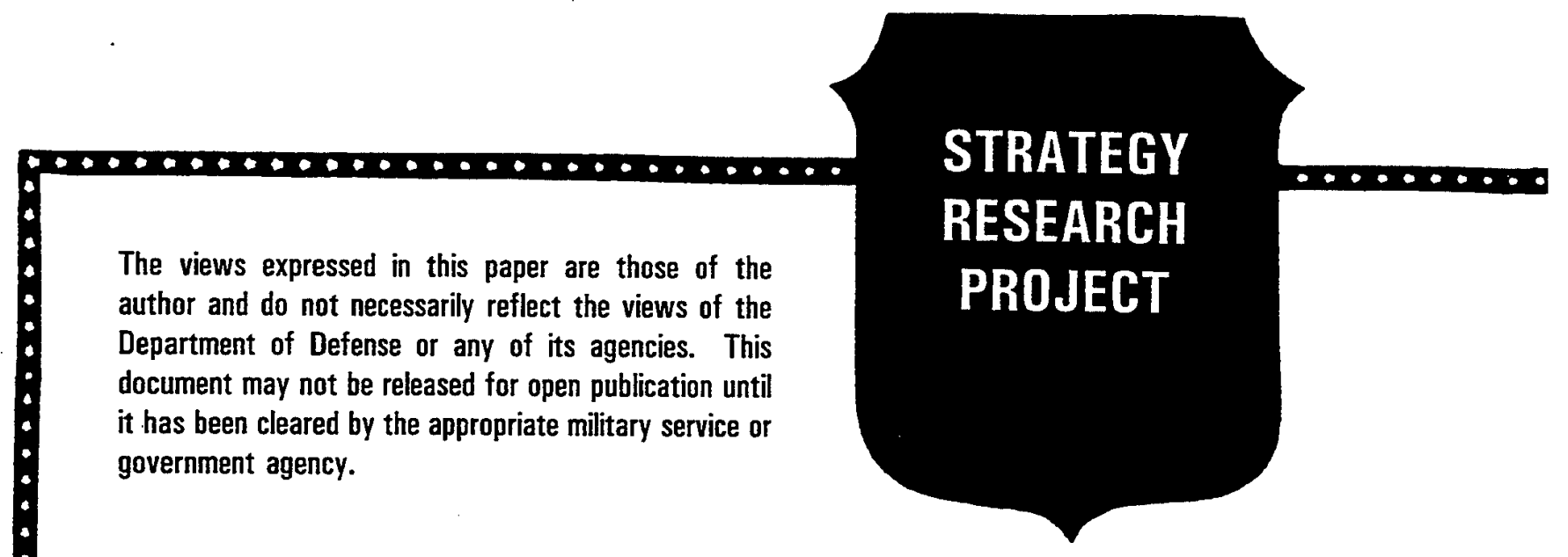

\title{
ADVANCING ARMY WOMEN AS SENIOR LEADERS - UNDERSTANDING THE OBSTACLES
}

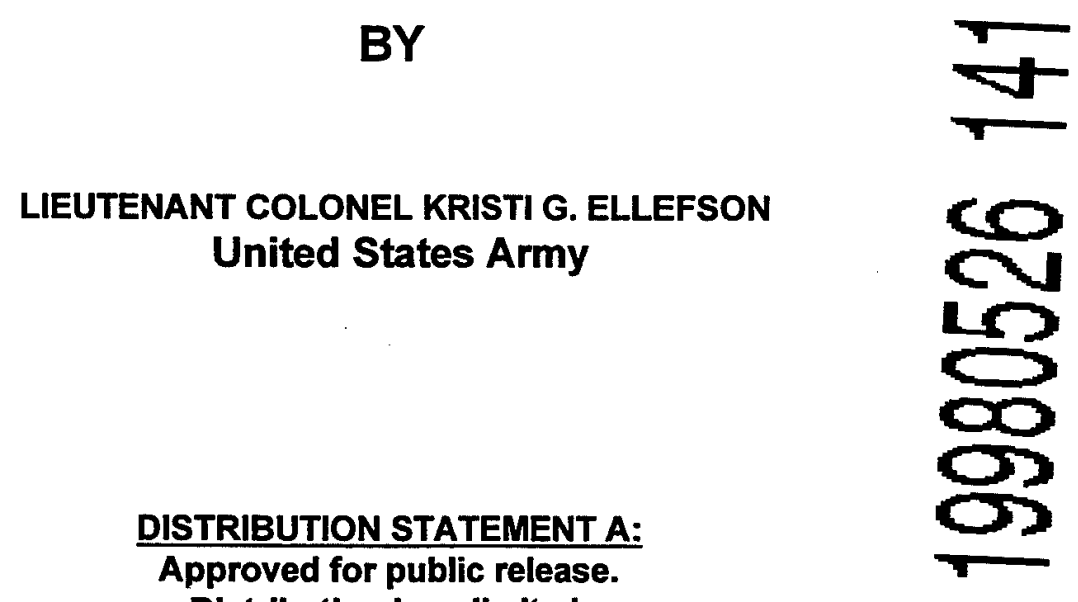

Distribution is unlimited.

DTIC QUALTTY INEPACTED 2

USAWC CLASS OF 1998

U.S. ARMY WAR COLLEGE, CARLISLE BARRACKS, PA 17013-5050 
USAWC STRATEGY RESEARCH PROJECT

\section{Advancing Army Women as Senior Leaders-Understanding the Obstacles}

LTC (P) Kristi G. Ellefson

Dr. Roderick R. Magee II
Project Advisor

The views expressed in this paper are those of the author and do not necessarily reflect the views of the Department of Defense or any of its agencies. This document may not be released for open publication until it has been cleared by the appropriate military service or government agency.

U.S. Army War College

CARLISLE BARRACKS, PENNSYLVANIA 17013

DISTRIBUTION STATEMENT A:

Approved for public release.

Distribution is unlimited. 
ABSTRACT

AUTHOR: $\quad$ ITC(P) Kristi G. Ellefson

TITLE: Advancing Army Women as Strategic Leaders-Understanding the Obstacles

FORMAT: Strategy Research Project

DATE: 20 January 1998 PAGES: 38 CLASSIFICATION: Unclassified

This paper examined through research, whether any evidence exists which indicates that, army women are confronted with inherent obstacles as they try to advance through the ranks to senior level positions. And, it explored that if in fact those obstacles do exist, does the culture of the army aid in fostering them. This study was conducted in an attempt to assist in determining the possible causes of women choosing not to remain in the service long enough to reach the senior grade levels. Are there just too many obstacles for women to face that in the end, it is just not worth any further effort? 


\section{TABLE OF CONTENTS}

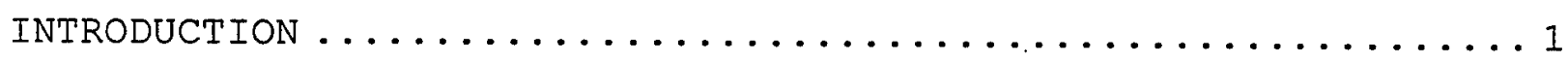

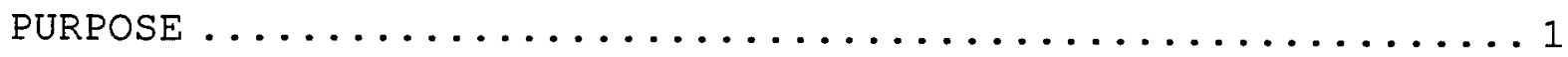

BACKGROUND $\ldots \ldots \ldots \ldots \ldots \ldots \ldots \ldots \ldots \ldots \ldots \ldots \ldots \ldots \ldots \ldots \ldots \ldots \ldots$

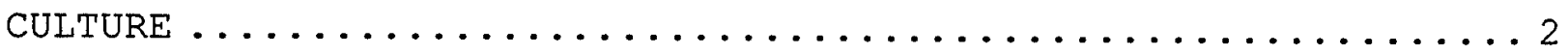

THE ARMY CULTURE ..........................

DOMINANTS $\ldots \ldots \ldots \ldots \ldots \ldots \ldots \ldots \ldots \ldots \ldots \ldots \ldots \ldots \ldots \ldots \ldots \ldots \ldots$

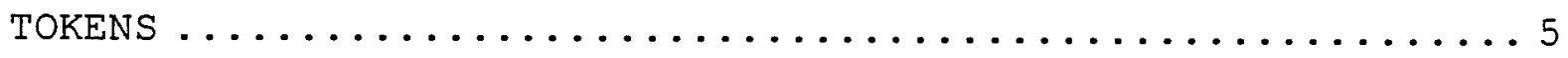

OBSTACLES $\ldots \ldots \ldots \ldots \ldots \ldots \ldots \ldots \ldots \ldots \ldots \ldots \ldots \ldots \ldots \ldots \ldots \ldots \ldots \ldots \ldots$

SOCIETAL VIEW OF TOKENS IN A 'MALE' OCCUPATION ..........

STEREOTYPING $\ldots \ldots \ldots \ldots \ldots \ldots \ldots \ldots \ldots \ldots \ldots \ldots \ldots \ldots \ldots$

LEADERSHIP BIAS ........................

PERCEIVED ABILITIES \& COMPETENCY ................. 11

BOUNDARY HEIGHTENING ...................... 13

ISOLATION $\ldots \ldots \ldots \ldots \ldots \ldots \ldots \ldots \ldots \ldots \ldots \ldots \ldots \ldots \ldots \ldots \ldots \ldots$

MENTORING ............................. 16

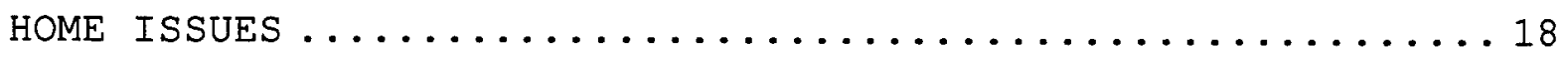

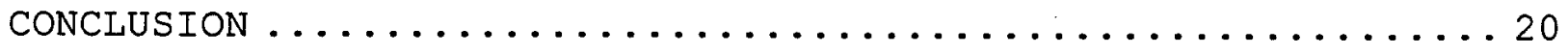

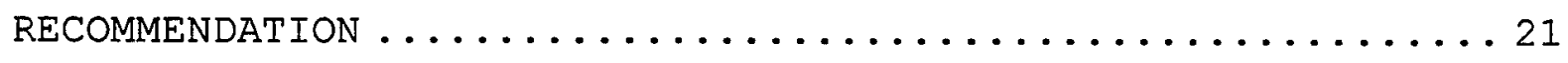

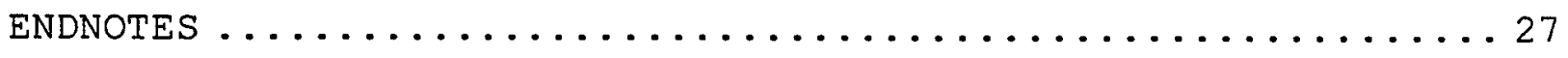

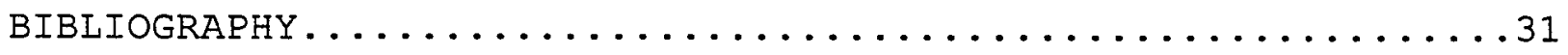




\section{INTRODUCTION}

\section{PURPOSE}

The purpose of this paper was to determine if research evidence exists, that indicates whether women are confronted with inherent obstacles as they try to advance through the army structure to senior level positions. And to explore that if in fact those obstacles do exist, does the culture of the army aid in fostering them. This study was done in an attempt to assist in determining the possible causes for women choosing not to remain in the service long enough to reach the senior grades.

\section{BACKGROUND}

In the 1970's the Defense Department began to seriously recruit women for active duty, not so much out of a desire to androgynize the military, but rather to save the All-Volunteer Force.' The women's presence lay more in the shortage of men available, and women were seen as a temporary fix to a difficult situation. That situation still exists today. The Army requires women to meet its quota, to fulfill its mission. Yet even still, there is a resistance to females in the service. As women progress through the ranks, their numbers significantly decrease at the higher-grade levels.

A briefing presented in October 1997 by the Army Deputy Chief of Staff Personnel (DCSPER) showed that the total percentage of commissioned female officers serving in 1997 is 14.3 . Of that 
total, 10.7 percent are in the grade of $0-5,6.5$ percent in the grade of 0-6 and only 2.7 percent reached grade of $0-7$ and above. $^{2}$ Concern is expressed by the senior Army leadership as to how to account for such an occurrence. What exactly is its cause? Are there just too many obstacles for women to face while trying to achieve senior rank?

This paper is an attempt to determine if there are specific reasons that possibly could affect the decision of army female officers in choosing early discontinuance of their careers. In conducting the research I found that the preponderance of studies available concerned civilian management structures. However, for the most part, their results can be extrapolated to fit the military experience. To understand the climate within which women operate, one must first have a basic knowledge of what is culture and then specifically, what is the Army's culture.

\section{CULTURE}

According to Webster's Dictionary culture is defined as "the skills, arts, etc. of a given people in a given period" ${ }^{3}$. Schein in his work on Organizational Culture and Leadership, further defines culture as:

A pattern of basic assumptions-invented, discovered, or developed by a given group as it learns to cope with its problems of external adaptation and internal integration-that has worked well enough to be considered valid and therefore, to be taught to new members as the correct way to perceive, think, and feel in relation to those problems. ${ }^{4}$ 
Schein further notes that "organizational cultures are highly 'visible' and 'feelable's and one of the most important areas of culture is the shared consensus on who is in and who is out and by what criteria one determines membership." ${ }^{6}$ This is a significant point to note when one looks at the culture and character of the Army.

\section{THE ARMY CULTURE}

The Army sees itself, ultimately, as the essential artisans of war, still divided into their traditional combat arms-the infantry, artillery, and cavalry (armor)-but forged by history and the nature of war into a mutually supportive brotherhood of guilds.?

The army by its very essential design is male dominated and strength is a prized and rewarded attribute. It is addressed in literature as a "brotherhood" and numerous novels have been written on that prevalent aspect. The assumptions of masculinity are deeply imbedded in the organizational processes and structures, so much so that they are nearly invisible. The services are not alone in the preponderance of males present in the hierarchical dominance of the military institutions. Corporate America also maintains an overwhelming majority of males in positions of influence within its civilian establishments.

Male dominance in practice has been maintained and developed through a system of ideas, reflecting asymmetrical cultural evaluations of male and female...an association of female with 'domestic' and male with 
'public' sphere of responsibility. In modern society the 'public' domain is very much an organizational domain. 8

As a result, masculine behaviors and values are considered the norm and feminine ones the deviant." 9 Thus, as in most large corporations the dominant group sets the terms of the culture and the characteristics of the institution. This action of the majority, whether knowingly or not, determines the environment in which all others in the group must operate. "The cultural association of masculinity and authority is reproduced through the decisions made by managers and supervisors who are concerned...not to disturb this 'natural' relationship."10 "The collective forces at work in the military culture demand women's marginalization. Accepting women as military peers is antithetical to the hypermasculine identity traditionally promoted by the institution and sought by many military men."11 This then is the environment, where males dominate, which women must understand as they make career decisions.

\section{DOMINANTS}

In studies conducted by Kanter on gender and its effect in the workplace, it was found that groups considered "skewed" have a majority to minority ratio ranging from 85:15 to 100:0. That effect typifies the male to female ratio of army officers.

"Members of sex in abundance in skewed groups are called 'dominants,' because they are seen to control the group and its culture, and members of the other sex are called 'tokens,' because they are more often 
treated as representatives of their sex than as individuals." 12

As a part of societal "norms" the workplace has

traditionally been associated with males, "so that when a women

enters they must be identified."13 Today this accounts for such an appellate as "female officer" as opposed to just "officer" or "female battalion commander" as opposed to "battalion commander".

\section{TOKENS}

Tokens do not merely differ from other group members along some particular dimension. They are categorized on the basis of an easily recognizable characteristic, such as sex, race, ethnic group, or age, characteristics that carry a set of assumptions about the token's traits and expected behavior. ${ }^{14}$

The particular status of token results in a number of internally created pressures that exist solely related to singularity. The situation is exacerbated relative to the smaller percentage of tokens in the skewed ratio. As such, the performance of tokens is detrimentally effected due to the special treatment they receive because of their status.

"First, because they are highly visible, tokens face
additional performance pressure. Second, the
differences between tokens and dominants tends to be
exaggerated. Third, the characteristics of tokens are
often distorted or misperceived because of the
dominants" tendency to stereotype them."15

The behavior of one 'token' is perceived as representing all the tokens in the organization. "They (females) have difficulty gaining the trust of their male co-workers, and are excluded from informal networks."16 This therefore sets the stage in which 
most men and women in the army operate. Due to the nature of the environment, research reveals that there are inherent obstacles with which tokens are presented.

\section{OBSTACLES}

\section{SOCIETAL VIEW OF TOKENS IN A 'MALE' OCCUPATION}

The sheer paucity of women in the army at senior grades means those officers invariably fall into the category of "tokens". Tokens have little difficulty in having their presence noticed but they do have problems having their competency recognized. ${ }^{17}$ "There is a great deal of research evidence...that female executives experience greater obstacles than their male counterparts...such as being excluded from information networks and not being recognized for their achievements." ${ }^{18}$ It appears from the research that this occurs only for women in predominantly male occupations. ${ }^{19}$

The concern of diversity in the army today may in and of itself cause an obstacle for women. "The organization...may attempt to show its enlightenment by displaying token women in ways that deny their individuality. At such occasions, women are singled out for the fact that they are female rather than for their particular accomplishments." 20 This type of action may be seen as an advantage by some, however it usually exacerbates an already strained situation, as dominants are not pleased with the attention the tokens receive. 
The situation for women in the military may be negatively affected due to the very nature of the occupation they have chosen.

Society has traditionally viewed women as out of place both in organizations responsible for the implementation of force and in applying lethal force as individuals. The use of lethal force is so strongly associated with our ideas of masculinity that the ability to use it is one of the defining traits of manhood. ${ }^{21}$

Societal view along with internal constraints from the organization may lead to increased pressure both in social and professional performance.

Token women react to such performance pressure in several different ways. They may try to overachieve relative to their peers.... Trying to capitalize on their rarity as tokens and turning it to their advantage is also unlikely to succeed because it risks the displeasure of dominants. Finally, token women may seek to be 'socially invisible' by avoiding events at which their token status would provide visibility and making little attempt to have their accomplishments known. ${ }^{22}$

No matter what their personal style of behavior, token women may act in ways that are contrary to feminine gender stereotype to avoid acting in limited preset roles with which the dominants are comfortable. When dominants are faced with a decision as to how to react to 'non-normal' situation, they often resort to the comfort level that stereotyping affords.

In research conducted by Kanter, she concluded that "the smaller the minority women find themselves to be in an organization, the greater their chances of being isolated and evaluated on the basis of sex role stereotypes. ${ }^{\prime 23}$ 


\section{STEREOTYPING}

A stereotype is the set of traits or characteristics that are attributed to all individuals who occupy a particular role...A stereotype exists when a broad cross section of the population agrees that certain traits or behaviors are commonly associated with a particular role. A role is the expected and actual behaviors or characteristics that are associated with a particular social 'status' in our society. ${ }^{24}$

The impact of sex-role stereotyping is significant in how masculine and feminine sex roles are viewed by society.

"The number of desirable traits associated with
masculinity is more than double the number of desirable
traits considered feminine. Second, the feminine
traits considered desirable are not ones that would be
considered important or valuable in most professions or
occupations. Thus men are seen as being aggressive,
independent, unemotional, objective, dominant, active,
competitive, logical, worldly, skilled in business,
adventurous, self-confident, and ambitious- all traits
that are related to the concept of competence. Women,
on the other hand, stereotypically are seen as being
exactly the opposite of men on all of these dimensions.
Desirable traits for women are being talkative, gentle,
tactful, religious, quiet, empathetic, aesthetic, and
expressive-traits associated with passivity. ${ }^{25}$

Thus extrapolating, if a woman acts in the same professional behavior, that is positive for a man, stereotypically she is perceived as behaving in a deviant manner. However if she is to operate in a dominants' environment, "the solution is to train women to be more like men, confirming once again the 'male is normal' hypothesis."26 Which ultimately results in a conflicting solution.

One consequence of sex stereotypes is that women are less likely to be chosen for traditionally male positions, such as those in senior management. This 
occurs because the perceived lack of fit between the job requirements and the stereotypic attributes ascribed to women leads to expectations that they will fail. ${ }^{27}$

These gender stereotypes can have a significant impact on how members are regarded in a work setting. "Contrary to predictions based on sexual managerial stereotypes women managers do not necessarily adopt a people-oriented style and men a task-oriented style. Most research found no sex differences... whatever differences appear seem to be a function of situational variables other than sex."28 The managerial stereotype however persists regardless of the fact that "stereotypes tend to become less important as experience increases." 29 The heavy bias of gender stereotyping translates further into the area of leadership and what constitutes a leader.

\section{LEADERSHIP BIAS}

"Our cultural preference for masculine can be seen most clearly in our definitions of leadership and preference for certain types of leaders...men are more likely to be leaders in our public and private organizations than are women." 30 our perception of what makes a good leader appear to be a gender preference in society toward masculinity.

In a study of men and women at all levels of a corporation, conducted by Ellen Fagenson, she discovered that "(1) perceived masculinity is related to position (the higher the position, the higher the perception of masculinity), (2) there was no relationship between sex and masculinity, yet there was a relationship between sex and femininity, 
masculinity is positively related to the perception of power, (4) men and women at upper levels see themselves as similarly masculine, and (5) position is related to sex-role identity. ${ }^{31}$

In further research conducted by Powell concerning perceptions of effective management he discovered that, "...management traits that can be classified as traditionally feminine or androgynous (e.g., caring, connected, supportive) were seen as detracting from perceptions of managerial effectiveness." 32

The results of numerous studies to date have led me to hypothesize that masculinity is, and continues to be the first level of evaluation at the executive level of management.... As a culture, we may be loath to admit that the first thing a leader must be is masculine. However, this may well be the case. In addition, a leader may not be able to show feminine characteristics until after they have proved their masculinity. Unfortunately for women, proving one's masculinity is not as easy as it is for men. Because of the deep cultural foundations of sex or gender roles, men prove their masculinity almost by default... Likewise, women prove their femininity almost by default. Women who want to be organizational leaders may be handicapped from the beginning by the expectation that they prove their masculinity. In addition, women may be faulted more for their femininity than are men." ${ }^{33}$

Therefore, while women are increasing in numbers in

leadership positions, "many are required to 'act like a man' inorder to succeed." ${ }^{34}$ This may in itself lead to personal

conflict and tension between a women's gender role socialization and the requirement and demands of a particular position. Stress levels may elevate as some women deem it necessary to behave one way at work and are required to behave differently at home.

Another aspect of the research finds that: 
Followers need additional reassurance from female leaders, forcing them continually to demonstrate and reassure followers of their competence. This is not the case with male leaders, who may even demonstrate incompetence without having their overall leadership called into questions. The situational terrain, then, differs by gender interpretation. ${ }^{35}$

This action results in another obstacle- that of a possible perceived lack of abilities and competencies on the part of tokens, which could affect their performance or career potential.

\section{PERCEIVED ABILITIES \& COMPETENCY}

While the skills of the dominant worker are normally cited as the reason for the accomplishment of their work, tokens may not be viewed in the same manner. They are often faced with the burden of stereotyping in determining the reasons for their success or failure in endeavors.

"Sex stereotyping has been shown to affect the evaluation of people's performance on tasks and the attribution of causes of good and poor performance." ${ }^{36}$ In various experimental studies it has been shown that "good female performance is perceived as due to effort, and good male performance as due to ability."37 This one particular perception has a potentially significant impact on tokens' performance evaluation and future career possibilities.

If, for instance, successful performance is attributed to ability, then one would suppose that the level of performance might be repeated for some time to come...If, on the other hand, the performance is due to effort, then this could be regarded as a temporary or situationally determined event, leading to no firm conclusion about future performance. ${ }^{38}$ 
In other research participants concluded that "...men's failure is attributed to (bad) luck, women's to (low) ability."39 Thus "women's achievements tend to be devalued or attributed to luck or effort rather than ability or skill..." "40 The corollary to this concept is that positions which women fill must not require much ability and "if jobs can be filled by women, they will come to be perceived as less difficult." ${ }^{41}$ Hence, there is some reluctance to having women fill some very traditionally male dominated positions. This may account for the anxiety in the military concerning back to back assignments of women in key leadership positions. The fear being that the position itself will come to be regarded as "pink" and thus one to be avoided, or a general feeling in the unit by the dominants that it must not be a challenging place to work. Ultimately, the position will be devalued by the institution and thus also the performance of the person filling the slot.

In a study of women managers of Fortune 500 companies, the conclusion reached was "that women are under enormous pressure to do outstanding work continuously and must consistently demonstrate competency on the job. ...Female managers have to work harder to gain credibility." ${ }^{42}$ But all that effort may simply be regarded as a necessity due to an innate lack of ability. In studies of law firms where the number of senior women partners was so few in very high power positions, even "the junior women seemed to question how the women partners got where they were and 
whether their authority was legitimate." ${ }^{43}$ While gender stereotyping appears to affect views of token capabilities it. also appears to exacerbate a process called boundary heightening.

\section{BOUNDARY HEIGHTENING}

In Kanter's work with groups she found a very interesting phenomenon occurring among skewed groups call "boundary heightening". "By their very presence, tokens make dominants more aware of what they have in common, while at the same time posing a threat to that commonality." 44 "...The dominant group tends to heighten its cultural boundaries through exaggerating the token women's differences from them and excluding the women from informal interactions where critical information is exchanged." ${ }^{45}$ In this context there is an attempt by the male dominants to accentuate what they can do personally (i.e. physical strength) as opposed to what women can do. As in the example of a male cadet at West Point stating "Man to man, woman to man, let's see how many push-ups you can do and let that determine our promotion. "46 or the dominants that establish some normative rule such as swearing and then challenging the tokens to confront or accept the status quo. ${ }^{47}$ The dominants may go out of their way to engage in an activity where they know tokens will be excluded and emphasize the fact to others.

Men leave token women with few choices for responding to heightening activities. They may accept isolation, opting for friendly but distant relations with the male members except at times when they are excluded. Or 
they may try to become insiders by defining themselves as exceptional members of their sex and turning against other women who attempt to join the group. ${ }^{48}$

This behavior was evidenced at West Point. "So valued was the male stamp of approval that the token female cadets embraced their sometimes puzzling status as a third sex.... We (female cadets) end up disparaging our own sex." ${ }^{49}$

If women however fight boundary heightening "they risk being classified as 'iron maidens' and face rejection by the group." ${ }^{50}$ It becomes a no-win situation.

As the status quo begins to shift those who support the way things used to be, begin to increase in resistance. Michael Kimmel, a sociologist at the State University of New York, wrote recently that:

Such a shift in the workplace has helped to change some old prejudices, but it has also produced a new tension between the sexes, as some men complain that women are competing for 'their' jobs. Sexual harassment has become a way for men to remind women that they are after all, 'just' women, who happen to be in the workplace but don't really belong there. ${ }^{51}$

The area of boundary heightening may be one causal effect of another obstacle senior level women may face, that of isolation.

\section{ISOLATION}

The higher the level of responsibility for women, the more prevalent the reality of isolation. "Presumably the higher a woman climbs, the lonelier she gets, because there is less support available from either women or men."52 "Women can't 
take for granted with whom they can associate, as they perceive the political consequences that may devolve from even the most casual or informal contact."53 Credibility and acceptance have long been achieved by blending in, however this method has gone to the extremes and ultimately never ends in a total acceptance by the dominants.

"For instance, women who appear to have been co-opted into male-dominated organizational strata are often painfully cognizant of the contradictions in which they are involved. On the one hand, they are frequently aware of the structural impediments to their full integration and yet the only way they can function is to ignore the knowledge. Women are thus often simultaneously 'immersed in and estranged from' their occupations."

Even if the senior level female officer is not the only woman in an organization she is still a minority. And her token status may be even more prevalent. Singularity does not always have its rewards. "What are the implications for women's Iives when they begin to enter the male culture of the organization in other than stereotypical female roles...?...findings suggest that such women have a strong and urgent need to know about each other's experiences..." "55 Another concern voiced by senior level women from various organizations was the lack of an informal information network. This leads to an area in which the army could be substantially improved, its mentoring program. 


\section{MENTORING}

Even though mentoring is known to be important in the development of successful senior leaders and "the benefits of having a mentor are legion," it is not an area that as yet is emphasized in the Army. There are of course army publications on the subject but it is not taught or addressed with any serious intent. This is not as consequential for males who are 'adopted' by an established network, but junior females are at a disadvantage in not knowing what to pursue.

Mentors can provide a myriad of substantial benefits to the protégé as well as substantially assisting the organization in producing well-prepared leaders for tomorrow. Mentors typically provide sponsorship, feedback, expertise, encouragement and professional career advice. "Countless ... studies have also confirmed that women with mentors enjoy greater job success and satisfaction than those who do not have one." 57

The obstacles appear for women in the attaining and sustaining of a mentor for various reasons. Most notably is that men who hold most of the senior positions, tend to choose someone "who reminds them of their sons or themselves when they were younger." 58 "Suitable mentors generally have been thought to be of the same sex as their proteges, so men have the advantage of the same sex role model and the benefit of access to the maledominant culture."59 This leads to a subsequent, intangible barrier for women in acquiring a mentor, in that men feel 
uncomfortable beside them. ${ }^{60}$ The "frequent interaction and intimacy in communication commonly associated in mentoring relationships may also deter cross-gender mentoring due to peer pressure and other organizational factors."61 And further, "the different interests of men and women, the jealousy of spouses or significant others, may interfere with the mentoring relationship." ${ }^{62}$

Even though "mentors play an important development role for individuals...even if they (women) recognize the importance of having a mentor, they may lack the skills necessary or see greater barriers to gaining one." ${ }^{63}$ Further, "many women don't actively seek mentors. Instead, they wait to be chosen. Or, they often fall into mentoring relationships without fully understanding the concept and are not comfortable being coached." ${ }^{64}$ It is not something one intuitively knows and there is not enough attention paid to this important aspect of growing senior officers.

While it is presumed that with more women assuming senior ranks this will correct the deficiency. Among females the obstacles previously addressed in this paper may prevent women from mentoring. Studies have revealed that both junior men and women prefer men as mentors because most women are not viewed as being in a position of true power based on ability nor are they formally 'connected'. ${ }^{65}$ And, in some instances, "it is a lack of time-rather than a lack of interest-that prevents them from 
mentoring other women. This is especially true of the small number of high visible women who have made it to the top and whose schedules are stretched to the limit."66 This also is a consequence of singularity. In the area of women mentoring women, experts on the subject say,

Entrenched institutional attitudes make it difficult for junior and senior women to form the kind of supportive relationships that may help many men navigate their careers. 'There's still this attitude that if there's two women talking together in a room they must be plotting a revolution'... The institutional barriers against female bonding are formidable. ${ }^{67}$

The aspect of mentoring and women is of considerable concern. It not only affects the work environment but the relationships cultivated during non-duty hours may escape some women because of obligations at home.

\section{HOME ISSUES}

Women, as they rise in the organization structure, face another obstacle that is not traditionally felt by most men. The majority of occupations are established to "suit a traditional male lifestyle, with a wife at home and thus with no extra responsibilities out side of work."68 "Regardless of her occupation, the woman still performs most household activities in dual-career families. Thus, having a family typically imposes a greater constraint on women's careers than it does on men's."69 Additionally, there may be the added burden of performing "role management" on and off the job. This may be one aspect that adds 
additional stress and causes women to exit the service before they reach higher level positions.

Time may also be constrained outside work hours, making it difficult to maintain informal contacts and networks. These activities which strengthen collegial ties may be beyond the tokens' reach. In the October briefing presented by the DCSPER, the statistics show that ninety percent of army male officers in the rank of Lieutenant colonel to General have children. Women officers in the same ranks may not, and of the total of twentyone Army female officers, who have made general officer level, none has ever had a child. ${ }^{70}$ It appears the obtaining of senior level careers of women, along with having children, has not happened in the army.

On the other side, female single officers are confronted with a mix of different home issues. They may be the caretakers of elderly parents, or as sole individuals, there may be no immediate support group to share the burden of daily demands and chores. Deployments then become complicated as most senior officers have established households and belongings, the single female must find someone to "tend the store" while they are gone. That may become increasing more stressful as the number of deployments expands. 


\section{CONCLUSION}

It is clear from the research that there are definite obstacles that confront army women on their path to senior level positions. The culture of the army and especially the issue of gender stereotyping appear to play the most significant role. The overwhelming preponderance of research for this project showed, "consistent with predictions based on skewed sex ratios, women at the highest executive levels reported more obstacles due to lack of personal support and less culture fit than did lower level executive women."

Tokens face a set of work conditions that differ from those of their numerically dominant colleagues and are particularly negative when the tokens are women in a male-dominated work setting and occupation. Although token or dominant status alone does not determine how one interacts with others, it does have an important influence on interactions between women and men in management ranks and in other types of groups. ${ }^{72}$

Findings from a study conducted by Lyness and Thompson revealed that women are possibly "confronted with a second, more subtle glass ceiling once they reach senior-level management position."73 The numbers of senior level women leaving the service may indeed be due to "burn-out" from experiencing more or repeated obstacles as they advanice without a support apparatus or a negative view that the obstacles will never abate.

However the good news is "male attitudes toward women workers are affected by personal experience with women on the job...men who have interacted with women peers longer are less likely to 
characterize them according to gender stereotype. ${ }^{174}$ Other studies have shown that:

Differences are most likely to appear in newly formed groups in which members have little information about each other's competence. Sex differences in task versus social roles played in newly formed groups seem to result from group members' belief in gender stereotype, particularly that males are more competent at tasks than females. However, when the group has some history and members have gained information about each other's competence, sex differences in interaction style tend to disappear. ${ }^{75}$

The likelihood of combat arms officers having some direct constant working relationship with females is slight, yet these are the individuals with the key leadership positions in the army that set the culture. It is not a women's issue, it is an army issue since valuable, trained, and highly experienced female personnel are leaving the service just when their contributions in senior levels could impact the organization. "When culture becomes dysfunctional, leadership is needed to help the group unlearn some of its cultural assumptions and learn new assumptions." ${ }^{76}$ What then is the recommendation?

\section{RECOMENDATION}

Tokenism, according to Kanter, cannot affect the majority decision process until the ratio reaches at least $65: 35$ and to achieve true balance the ratio of $60: 40 .^{77}$ Since this will most likely never be a reality in the Army, nor is this author's intention to advocate those percentages, it does however beg the question then what should be done about the current situation. 
The army is increasingly dependent on women to perform its mission, however among dominants the contribution of women is not valued. Rather it is still viewed as a temporary fix that would be rectified if the right number of men could be obtained. Women in senior leadership roles should "not be perceived as à 'diversity' hire, but as an asset to the corporation."78

"...Increasing the number of women in positions of power and responsibility without a commensurate increase in the perception of their suitability for these positions is unlikely to effect much social change." 79

On the part of the senior military establishment a number of steps should be taken. First, "one of the best mechanisms that ...leaders...have available for communicating what they believe in or care about is what they systematically pay attention to." ${ }^{80}$ The senior leadership should emphatically state that women's contribution is a valued commodity and that the women in the army are essential to the mission. The dominants must have an accurate understanding that it is not possible to accomplish the army's mission without them and that they are integral to the current functioning of the organization. Second, the reality of tokenism and gender stereotyping should be understood and addressed. Knowledge is the best defenses against ignorance and disparagement. It often is enlightening just to realize why one may subconsciously act in a particular manner. If they choose to continue, ignorance is no longer a valid excuse. "When gender. 
stereotyping enters into a work relationship, the male's perception of the female is influenced more by the feminine stereotype than by her actual traits and behaviors..." ${ }^{81}$ Curtailing gender stereotyping is not beyond the leaderships' control. Although organizations cannot ban gender stereotyping from the workplace, they have too much to lose from its negative effects to ignore the issue altogether.

Third, gender stereotyping diminishes over time when individuals gain experience "working with opposite-sex peers and also when they work with greater numbers of opposite-sex peers at a given time." ${ }^{82}$ Male officers who are not in a position to work routinely with women should take advantage of the opportunity to do so when it is afforded on various military exercises and exchanges, and be positively encouraged in the endeavor by their senior leaders.

In a recent study of managerial men in corporate America, for example, male managers who had worked with women as peers were less likely to stereotype women as unfit for managerial roles than were those who had only worked with women as subordinates. In other words, familiarity appears to breed less contempt. ${ }^{83}$

Fourth, women need to understand the concept of tokenism as well as men, to be able to deal with the circumstances by possessing the right attitude. They may not like what is happening but they will be better equipped to confront the challenge with a positive perspective. "Even managers who said they had encountered obstacles refused to be sidetracked-either by ignoring these obstacles or by finding ways to get around 
them. In fact, many of the managers we interviewed felt that what often separates 'victims' from those who refuse to be waylaid is attitude." ${ }^{84}$

Fifth, it behooves the senior army leadership to address these issues with the junior women who are entering the service. Forewarned is forearmed. The young women entering the army may find the obstacles too much too soon and good talent could be leaving the army before being given a chance. The young female officer should also be honestly told what they might encounter as they progress in rank and their numbers decrease. This will better equip them to decide whether to remain in the army or make an early career change.

Sixth, the aspect of mentoring for women must be addressed early in a woman's career. "Mentoring can benefit all parties involved, including the organization." ${ }^{85}$ Assigning mentors is not necessarily the answer. "Those ordered to mentor may lack the time, inclination, interpersonal skills, or particular knowledge their assigned protégé may require."86 Instead, women should be encouraged to seek a number of mentors to acquire a wide range of information and assistance. They must learn that they need to take control of the situation and be proactive. If they wait to be chosen, they may lose out. And, senior male officers should be encouraged to mentor females. There are perceived problems to cross-gender mentoring. Male officers express concern over the possible impact it could have on their 
careers. They prefer avoidance rather than to entertain any potential gender issues associated with mentoring the opposite sex. However, creative ways can be conceived, such as counseling via the Internet, to transcend most difficulties. While there are other obstacles not mentioned in this paper, the ones chosen are the most prevalent to senior level women in the Army. These are not however, insurmountable. As in other problematic areas, leadership is key, along with an honest desire by the dominants in this instance, to see the circumstances change. It not only may increase the likelihood of more women remaining longer but also will ultimately benefit the army as a whole. 6,685 


\section{ENDNOTES}

Linda Bird Francke, Ground Zero: The Gender wars in the Military (New York, NY: Simon \& Schuster, 1997), 18.

2 ITG Vollrath, DCSPER, Briefing entitled "Women in the Army" presented to the Army War College, 24 October 1997.

3 Webster's New World Dictionary (1983).

4 Edgar H. Schein, Organizational Culture and Leadership (San Fransico, CA: Jossey-Bass, 1992), 9.

5 Ibid., 24.

6 Ibid., 66 .

7 Carl H. Builder, The Masks of War (Baltimore, MD: The Johns Hopkins University Press, 1989), 33.

8 Albert J. Mills and Peta Tancred, eds., Gendering Organizational Analysis (Newbury Park, CA: Sage Publications, 1994), 94 .

9 Ann Harriman, Women/Men/Management (Westport, CT: Praeger Publisher, 1996), 2 .

10 Mills, 19.

11 Francke, 157.

12 Gary N. Powell, Women \& Men in Management (Newbury Park, CA: Sage Publications, 1993), 111.

13 Harriman, 124.

14 Powel1, 113.

15 Powell, 113.

16 Uma Sekaran, and Frederick T. L. Leong, eds., Womanpower: Managing in Times of Demographic Turbulence, (Newbury Park, CA: Sage Publications, 1993), 18.

17 Powell, 113.

18 Karen S. Lyness, and Donna E. Thompson, "Above the Glass Ceiling? A Comparison of Matched Samples of Female and Male Executives," Applied Psychology 82, no.3, (1997): 361.

19 Ibid.

20 Powell, 113.

21 Ruth H. Howes, and Michael R. Stevenson, eds., Women and the Use of Military Force, (Boulder, CO: Lynne Rienner Publishers, 1993), 209.

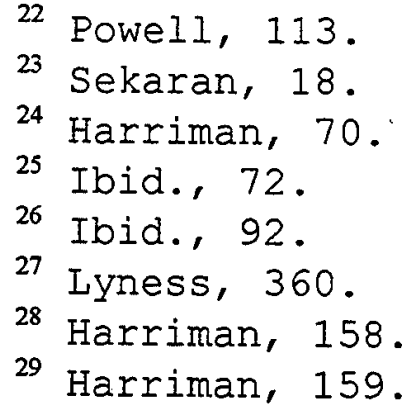


30 Georgia Duerst-Lahti, and Rita Mae Kelly, eds., Gender Power, Leadership, and Governance, (Ann Arbor, MI: The University of Michigan Press, 1995), 69.

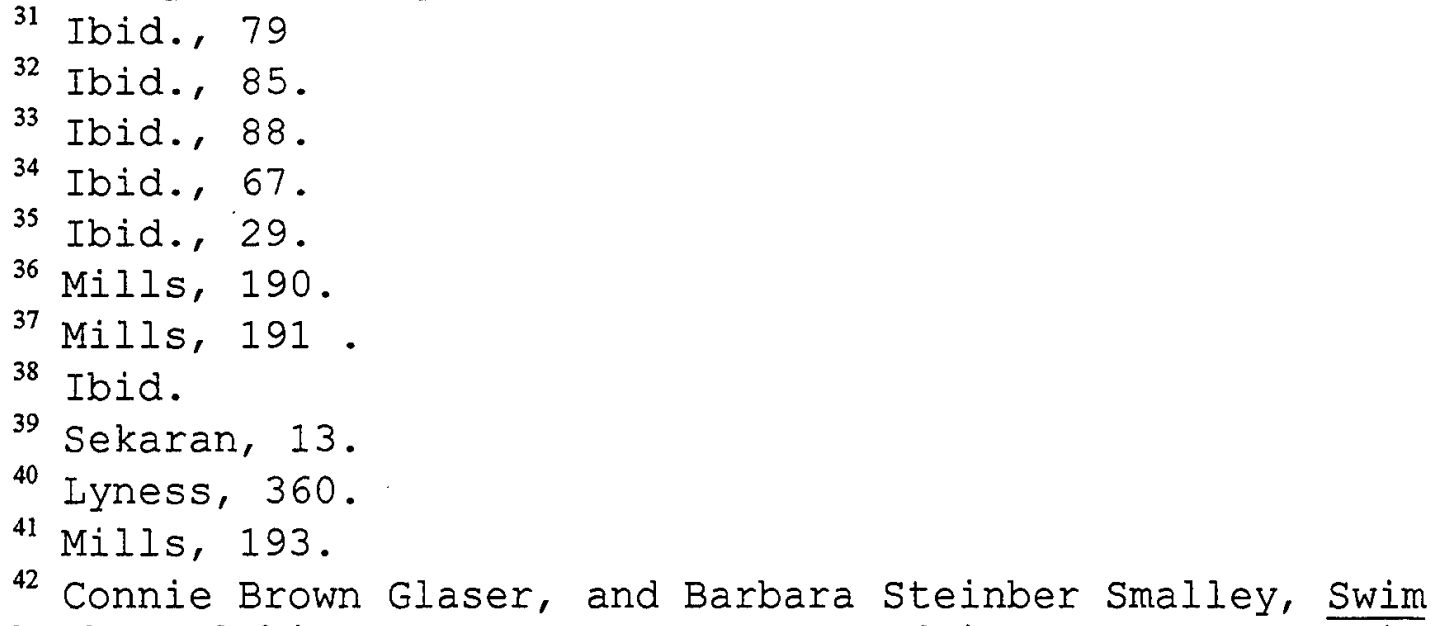

with the Dolphins: How Women can Succeed in Corporate America on Their Own Terms, (New York, NY: Warner Books, 1996), 283.

43 Amy Saltzman, "Woman Versus Woman," U.S. News (25 March 1996), Available from

http://WWw. usnew.com/usnews/ISSUE/WOMEN.HTM. Internet. Accessed 13 October $1997,3$.
44 Powell, 114.
45 Lyness, 362.
46 Francke, 198.
47 Mills, 158.
48 Powell, 115.
49 Francke, 211.
50 Powell, 114.
51 Glaser, 290.

52 Sekaran, 17. From a study conducted by Furkranester \& Furman, 1983.

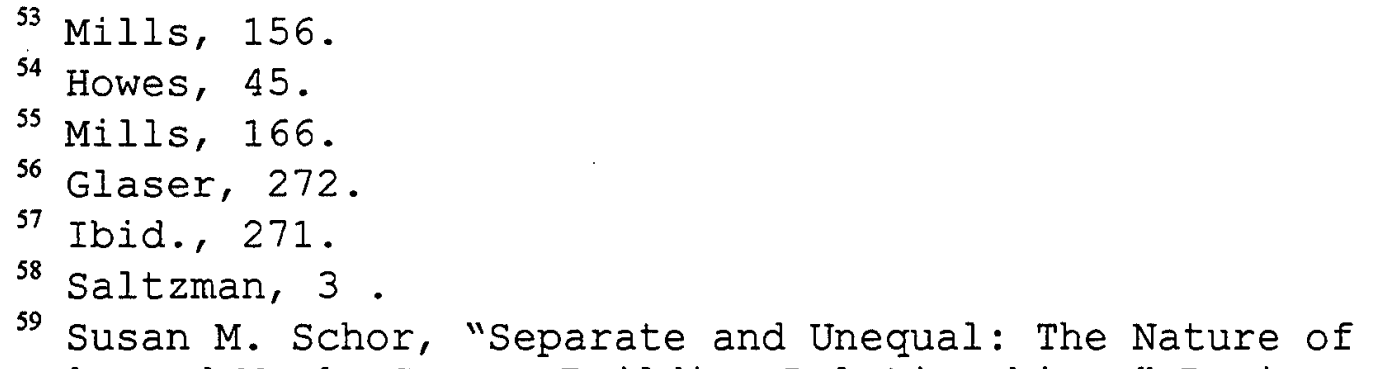

Women's and Men's Career-Building Relationships." Business Horizons, 40 no.5 (September-October 1997): 51-58.

60 Julie Stacey, "Opening Jobs to Women Still Low on Priority List, USA Today, 24 October 1997, sec 1, p. 13. In a Rand study, some commanders admitted they aren't comfortable working closely with women. 
61 Mary M. Sullivan, LCDR, "Mentoring in the Military: A Preliminary Study of Gender Differences," September 1993, 3. Available from http://Www.pafb.mil/DEOMI/mentors.htm. Internet. Accessed 26 October 1997.

62 John Hoschette, "Mentors-We All Need Them," Available from http://Www.mews.org/AIAA-NE/career/careet3.htm. Internet.

Accessed 13 October 1997, 2.

63 Powell, 207.

64 Glaser, 272 .

65 Sekaran, 207.

66 Saltzman, 4.

67 Ibid., 2.

68 Howes, 43.

69 Powell, 255.

70 Vollrath Briefing.

71 Lyness, 371.

72 Powell, 116.

73 Lyness, 373.

74 Powell, 111.

75 Powell, 105.

76 Schein, 317.

77 Francke, 259.

78 Amanda Fox, and Paul Ray Berndtson, "Recruiting and Retaining Women and Minorities for Management Positions," 1995, 3. Available from http://www.prg.com/glasceil.html. Internet. Accessed 14 October 1997.
79 Sekaran, 19
80 Schein, 224.
81 Powell, 116.
82 Powell, 116.
83 Glaser, 290.
84 Glaser, 282.

85 "Guidelines on Mentoring for Women," 25 November 1996. Available from http: //adminwww. flinders.edu.au/womensinfo/mentoring.html. Internet. Accessed 7 October 1997, 2 .

86 Schor, 56 . 


\section{BIBLIOGRAPHY}

"Advancing Women." 1995. Available from <http://www.advancing women.com/mentor/phtml Internet. Accessed 14 October 1997.

Builder, Carl H. The Masks of War. Baltimore, Maryland: The Johns Hopkins University Press, 1989.

Benveniste, Guy. The Twenty-First Century organization. San Francisco, CA: Jossey-Bass Publishers, 1994.

Bonnell, Karen H. "Career Success Tied to Mentoring." October 1996. Available from

http://cedar.evansville.edu/rtvjweb/static/oct96/mentor.html. Internet. Accessed 7 october 1997.

"Career Development for Senior Women Managers." NISW Notice Board Summer 1996. Available from <http://www.nisw.org.uk/notice/not/sum967.html>. Accessed 13 October 1997.

Duerst-Lahti, Georgia, and Rita Mae Kelly, eds. Gender Power, Leadership, and Governance. Ann Arbor, MI: The University of Michigan Press, 1995.

Fox, Amanda, and Paul Ray Berndtson. "Recruiting and Retaining Women and Minorities for Management Positions." 1995. Available from <http://www.prb.com/glasceil.html.> Internet. Accessed 14 October 1997.

Francke, Iinda Bird. Ground Zero: The Gender Wars in the Military. New York, NY: Simon \& Schuster, 1997.

Glaser, Connie Brown, and Barbara Steinberg Smalley. Swim with the Dolphins: How Women can Succeed in Corporate America on Their Own Terms. New York, NY: Warner Books, 1996.

"Guidelines on Mentoring for Women." 25 November 1996. Available <http//adminwww. flinders.edu.au/womensinfo/mentoring.html>. Internet. Accessed 7 october 1997.

Harriman, Ann. Women/Men/Management. Westport, CT: Praeger Publishers, 1996.

Himelstein, Linda, and Stephanie Anderson Forest. "Breaking Through." Business Week, 17 February 1997, 64-70. 
Hoschette, John. "Mentors-We All Need Them." Available from <http://Www.mews.org/AIAA-NE/career/careet3.htm>. Internet. Accessed 13 October 1997.

Howes, Ruth H., and Michael R. Stevenson eds. Women and the Use of Military Force. Boulder, CO: Iynne Rienner Publishers, 1993.

Johnson, Maryfran. "Mentor This!" Computerworld, 23 June 1997, 36.

Lyness, Karen S., and Donna E. Thompson, "Above the Glass Ceiling? A Comparison of Matched Samples of Female and Male Executives." Journal of Applied Psychology 82, no. 3 (1997): $359-375$.

Mills, Albert J., and Peta Tancred eds. Gendering Organizational Analysis. Newbury Park, CA: Sage Publications, 1994.

Moskai, Brian S. "Women Make Better Managers." Industry Week, 3 February 1997, 17-19.

Powell, Gary N. Women \& Men in Management. Newbury Park, CA: Sage Publications, 1993.

Saltzman, Amy. "Woman Versus Woman." U.S. News, 25 March 1996. Available <http://wWw. usnews.com/usnews/ISSUE/WOMEN. HTM>. Internet. Accessed 13 October 1997.

Schein, Edgar H. Organizational Culture and Leadership. San Francisco, CA: Jossey-Bass, 1992.

Schor, Susan M. "Separate and Unequal: The Nature of Women's and Men's Career-Building Relationships." Business Horizons 40, no. 5 (September-October 1997): 51-58.

Sekaran, Uma, and Frederick T. L. Leong, eds. Womanpower: Managing in Times of Demographic Turbulence. Newbury Park, CA: Sage Publications, 1993.

Stacey, Julie. "Opening Jobs to Women Still Low on Priority List." USA Today, 24 October 1997, sec. 1, p. 13.

Stephenson, Carol. "Toward a Female Model." Vital Speeches of the Day 63, no. 7 (15 Jan 97): 202-205.

Sullivan, Mary M., LCDR. "Mentoring in the Military: A Preliminary Study of Gender Differences." September 1993. Available from <http://www.pafb.mil/DEOMI/mentors.htm>. Internet. Accessed 26 October 1997. 
Terry, Jo Carol, COL. "Leadership Development of Senior Military Women in the Army." Strategic Research Project, U.S. Army War College, Carlisie Barracks, PA, (17 May 1996) (Unpublished).

Webster's New World Dictionary (1983)

Wood, Gail W. "Mentoring: A Useful Concept for Leader Development in the Army?", Strategic Research Project, U.S. Army War College, Carlisle Barracks, PA, (11 April 1990) (Unpublished).

"Your Life." USA Today (March 1997): 6-7. 